\title{
eMRA: Extension of MRA Considering the Relationships Between MDR Concepts
}

\author{
Young-min $\mathrm{JoO}^{+} \cdot$ Jangwon $\mathrm{Kim}^{++} \cdot$ Dongwon Jeong ${ }^{+++} \cdot$ Doo-Kwon Baik ${ }^{++++}$
}

\begin{abstract}
Metadata registry (MDR) is the international standard, developed by ISO/IEC for exchange and sharing data between databases. Many MDR systems are used in diverse domains such as medical service, bibliography, environment for sharing and integrating data. However, those systems have different physical structures individually because the MDR standard defines only the metamodel for registering and storing metadata. It causes heterogeneity between the system structures and requires additional cost to maintain interoperability. ISO/IEC 13249-8 Metadata Registry Access (MRA) is developing as an international standard to provide a consistent access facility to data stored in different metadata registries. However, MRA does not consider the relationships between the concepts (classes) defined in the MDR specification. It causes that incorrect query results returned from MDR systems. It also requires additional cost of modeling and rewriting queries to reflect each physical model. Therefore, this paper suggests eMRA which considers the relationships between the concepts in MDR. The comparative evaluations are described to show the advantages of eMRA. eMRA has superior performance in query modeling and referential integrity than MRA defined by the relationship between the concept of MDR.
\end{abstract}

Keywords: Metadata Registry, ISO/IEC 13249-8, MRA, SQL, Standard Interface

\section{$\mathrm{eMRA}: \mathrm{MDR}$ 의 개념간 관계성을 고려한 $\mathrm{MRA}$ 확장}

\author{
주 영 민 ${ }^{\dagger}$ 김 장 원 ${ }^{++} \cdot$ 정 동 원 ${ }^{+++} \cdot$ 백 두 권
}

\section{요 약}

메타데이터 레지스트리(Metadata Registry, MDR)는 데이터베이스 간 데이터 교환 및 공유를 위해 $\mathrm{ISO} / \mathrm{IEC}$ 에서 개발한 국제 표준이며, 의 료 서비스, 서지, 환경 등 다양한 도메인에서 데이터 공유 및 통합을 위해 사용되고 있다. 그러나 $\mathrm{MDR}$ 표준은 메타데이터 등록 및 저장을 위 한 메타모델만을 정의하고 있기 때문에 이 시스템들은 서로 다른 물리적 구조를 가지게 된다. 이로 인해 $\mathrm{MDR}$ 시스템 간 불일치가 발생하고 메타데이터의 상호운용을 위해 추가적인 비용이 발생한다. 이러한 문제를 해결하기 위해 ISO/IEC 13249-8 Metadata Registry Access (MRA) 가 개발 중에 있으며, $\mathrm{MRA}$ 는 상이한 $\mathrm{MDR}$ 시스템에 일관된 방법으로 접근할 수 있는 표준 인터페이스이다. 그러나 $\mathrm{MRA}$ 는 $\mathrm{MDR}$ 표준에 정 의되어 있는 개념 즉, 클래스 간 관계성을 고려하지 않는다. 이는 부정확한 결과를 생성할 수 있으며, 각 $\mathrm{MDR}$ 시스템의 물리적 구조를 고려하 여 질의를 모델링하고 재작성하는 추가적인 비용이 발생한다. 이 논문에서는 클래스 간 관계성을 고려한 확장된 인터페이스 eMRA(Extened $\mathrm{MRA}$ )를 제안하며, 비교 평가를 통해 확장 인터페이스의 장점을 기술한다. $\mathrm{eMRA}$ 는 $\mathrm{MDR}$ 의 개념간 관계성을 정의하여 질의 모델링과 시스템 의 참조무결성 측면에서 MRA보다 우수한 성능을 가진다.

키워드 : 메타데이터 레지스트리, ISO/IEC 13249-8, MRA, SQL, 표준 인터페이스

※ 이 연구에 참여한 연구자는 '2 단계 $\mathrm{BK} 21$ 사업'의 지원을 받았으며, 2012 년도 정부(교육과학기술부)의 재원으로 한국연구재단의 지원을 받아 수행 된 기초연구사업(NO.2012-0002439)의 결과물임을 밝히며, 또한 이 논문은 2012년도 정부(교육과학기술부)의 재원으로 한국연구재단-차세대정보·컴 퓨팅기술개발사업의 지원을 받아 수행된 연구임(No.2012M3C4A7033346).

† 준 회 원 : 고려대학교 컴퓨터·전파통신공학과 석사과정

† 준 회 원: 고려대학교 컴퓨터. 전파통신공학과 박사

†† 준 회 원 : 고려대학교 컴퓨터·전파통신공

†+1 종신회원 : 고려대학교 컴퓨터·전파통신공학과 교수 논문접수 : 2012년 9월 11일

수 정 일 : 1 차 2012년 11월 8일 심사완료 : 2012년 11월 27일

* Co-corresponding Author:Doo-Kwon Baik(baikdk@korea.ac.kr) Dongwon Jeong(djeong@kunsan.ac.kr)

\section{1. 서 론}

메타데이터 레지스트리(Metadata Registry, MDR)는 메타 데이터의 등록과 인증을 통하여 표준화된 데이터를 유지 및 관리를 하는 국제 표준이다[1,2]. 또한 메타데이터의 명세 및 의미 공유를 통해 데이터의 상호운용성을 향상시킨다[3-5]. 이러한 $\mathrm{MDR}$ 의 장점에 기인하여, 현재 다양한 분야에서 $\mathrm{MDR}$ 시스템을 개발하여 운영하고 있다[6,7]. 그 중 대표적 인 시스템으로는 호주의 보건, 주택, 공동체 서비스를 위한 통계 및 정보에 대한 국가차원의 메타데이터 관리를 위한 
$\mathrm{METeOR}[8]$, 미국의 건강 표준개발기관과 관련 기관 사이 의 데이터 요소(Data Element)를 분류하는 USHIK[9] 및 환 경 정보에 대한 기록을 표준화하여 사용자 간의 데이터 공 유를 가능하게 하는 $\mathrm{EDR}[10]$, 암 협회의 $\mathrm{caDSR}[11]$, 홈 랜 드 보호부와 법무부의 $\mathrm{NIEM}[12]$, 법무부의 GJXDM[13], 국 회 도서관의 $\mathrm{LC}[14]$ 등이 있다. 이 외에도 캐나다의 보건 정보부의 $\mathrm{CIHI}$ 데이터 사전[15], 영국의 암 그리드 기관의 암 그리드 $\mathrm{MDR}[16]$, 도서관 교육 그리고 문화유산 커뮤니 티의 디지털 정보 관리 서비스를 제공하는 UKOLN[17] 등 이 있다.

국내에서도 $\mathrm{MDR}$ 을 기반으로 데이터 통합시스템, 데이터 상호운용, 지리정보, 온톨로지, 서지정보 시스템, 등 다양한 분야에서 연구되고 있으며, 그 중에서도 정보통합 시스템 [18,19]과 상호운용성[20]에 관련한 연구가 주를 이루고 있다.

앞서 언급하였듯이, 다양한 도메인에서 서로 다른 $\mathrm{MDR}$ 시스템들이 개발되어 사용되고 있다. 그러나 $\mathrm{MDR}$ 표준에서 정의한 개념 모델을 일부 수정하거나 서로 다른 저장 모델을 개발하였다. 또한 각각의 저장 모델을 위한 서로 다른 접근 방법을 사용한다. 이러한 이질적인 구조 및 접근 방법은 서 로 다른 $\mathrm{MDR}$ 시스템에 저장되어 있는 데이터의 공유 및 재 사용을 어렵게 하는 문제점을 야기한다. 또한 데이터 접근을 위한 인터페이스가 각각의 시스템에 종속적이므로, 사용자가 원하는 데이터 요소들을 가져오기 위해서는 각각의 인터페이 스 구조를 파악해야 하는 오버헤드가 발생한다[21].

이러한 문제점을 해결하기 위해 ISO/IEC JTC $1 / \mathrm{SC} 32 / \mathrm{WG}$ 4에서는 ISO/IEC 13249-8 Metadata Registry Access (MRA) 표준이 제안되었다[22]. MRA는 $\mathrm{MDR}$ 에 정의된 클 래스에 저장된 데이터에 접근하는 목적을 가진다. 그러나
$\mathrm{MRA}$ 는 접근에 대한 기본적인 데이터타입만을 제공할 뿐, 구현을 위한 상세한 명세를 제공하지 않는다. 이는 MRA의 실용적인 활용성과 기능성의 한계를 가져온다. 따라서 상세 하고 다양한 기능을 제공할 수 있는 질의 인터페이스의 확 장이 요구된다. 이 논문에서는 이러한 문제점을 해결하기 위해 MRA 기반의 확장된 질의 인터페이스를 제안한다. 이 를 위해 $\mathrm{MRA}$ 의 기능 확장을 위해 요구되는 사항을 정의하 고 이를 해결할 수 있는 방안에 대하여 기술한다. 또한 실 제 질의 인터페이스를 구현하고 비교 평가를 통해 제안 모 델의 장점을 보인다.

이 논문의 구성은 다음과 같다. 2장에서는 관련연구를 소 개하고 3 장에서 기존 $\mathrm{MRA}$ 의 문제점을 기술한다. 4장에서는 이 논문에서 제안하는 $\mathrm{MRA}$ 적용방법에 대해 기술한다. 5장 에서는 적용한 시스템의 타당성을 검증하기 위한 비교 평가 를 하고 6 장에서 결론 및 향후 연구에 대해 기술한다.

\section{2. 관련 연구}

Fig. 1은 $\mathrm{MDR}$ 의 정보를 이용하기 위한 접근 방법 즉, 직 접적인 데이터 접근방법, 어댑터 기반 접근 방법, 바인딩 $\mathrm{API}$ 기반 접근 방법, $\mathrm{SQL}$ 기반 접근 방법 4가지를 보여준다[8]

Fig. 1의 a)는 $\mathrm{MDR}$ 시스템에 직접 접근하는 방법이다. 이 방법은 구축된 시스템의 구조를 정확하게 파악하고 있어 야 가능하고, 보안상의 문제가 있기 때문에 일반적으로 사 용되지 않는다.

Fig. 1의 b)는 어댑터 기반 접근 방법이다. 이 방법은 사 용자와 기관, 상호 간 공동의 어댑터 즉, 인터페이스를 개발

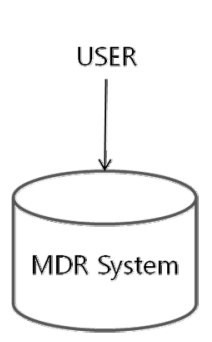

a) 직접적인 데이터 접근 방법

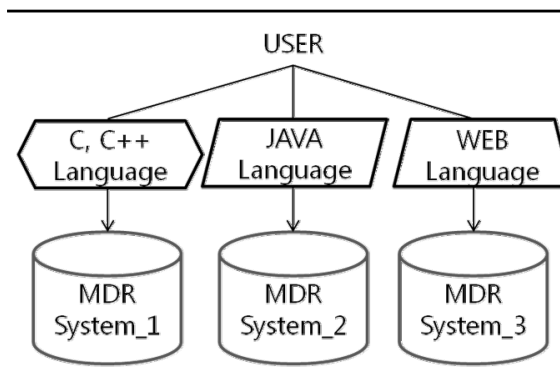

c) 바인딩 API 기반 접근 방법

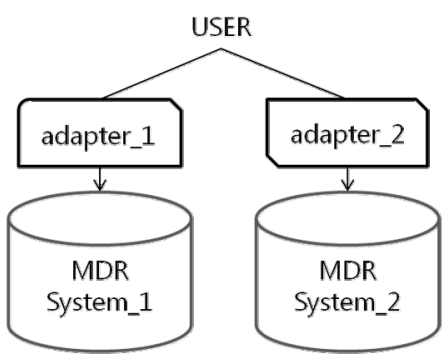

b) 어댑터 기반 접근 방법

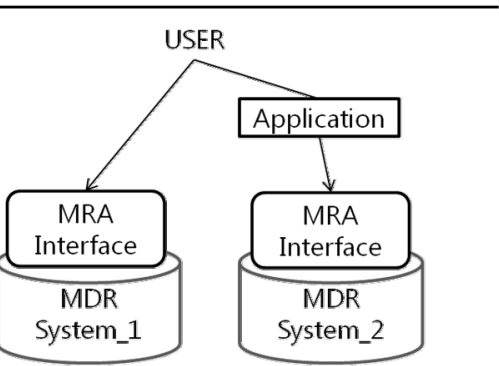

d) SQL 기반 접근 방법

Fig. 1. Four ways to access the MDR system 
해야 한다. 그러나 어댑터 기반의 접근 방법은 시스템의 물 리적인 구조에 의존적이기 때문에 사용자가 접근하고자 하 는 $\mathrm{MDR}$ 시스템이 여러 개가 존재할 경우 각각의 시스템에 적용할 수 있는 어댑터를 개발해야 한다. 그러므로 어댑터 개발을 위한 추가적인 비용이 요구된다.

Fig. 1의 c)는 바인딩 $\mathrm{API}$ 를 이용하여 데이터에 접근하는 방법이다[23,24]. [23]은 C, C++, 자바, 웹 프로그래밍 언어 등과 같은 프로그래밍 언어를 기반으로 $\mathrm{MDR}$ 시스템에 접 근할 수 있도록 각 언어별로 바인딩 $\mathrm{API}$ 를 정의한다. 또한 미국 암 센터에서는 웹 프로그래밍 언어를 기반으로 하여, 다양한 $\mathrm{MDR}$ 에 접근하는 방법을 개발하였다[24]. 이러한 방 법들을 통해 $\mathrm{MDR}$ 시스템에 접근할 경우, 사용자들은 프로 그램 언어에 따라 해당 언어 기반의 API를 파악해야 하므 로 추가 비용이 발생한다.

Fig. 1 의 d)는 SQL 기반 접근 방법이다. $\mathrm{SQL}$ 기반 접근 방법은 메타데이터를 가져오기 위해 SQL을 사용하는 방법 이다[25]. SQL은 데이터베이스에 저장되어 있는 데이터를 얻기 위한 표준 질의 언어이다. 따라서 $\mathrm{SQL}$ 을 이용하면 사 용자들이 일관성 있는 문법을 기반으로 데이터에 접근하는 것을 가능하게 한다.

$\mathrm{MRA}$ 는 앞에서 나열한 4 가지 접근 방법들 중에서, 사용 자에게 일관성 있는 데이터 접근을 가능하게 하는 $\mathrm{SQL}$ 기 반의 방법을 적용한다[26]. 특히 $\mathrm{MDR}$ 에서 정의하고 있는 각각의 클래스들을 $\mathrm{SQL}$ 에 정의된 사용자 정의 타입 (User-defined type, UDT)을 기반으로 정의한다[27,28]. 하 지만 기존 연구들은 $\mathrm{MDR}$ 표준에 있는 메타 모델들 간의 관계성을 고려하지 않는다. 그 결과 $\mathrm{MRA}$ 는 표준화된 인터 페이스를 지원하기 위해 $\mathrm{SQL}$ 을 적용하지만, 실제 환경에서 중요한 정보로 활용되는 메타 모델들 간의 관계 정보가 누 락될 수 있다. 또한 관계성을 통한 다양한 정보를 획득하기 위해 추가적인 연산을 수행해야 하며, 따라서 $\mathrm{MRA}$ 의 개발 목적이자 MRA에서 해결하고자 했던 목표인 상이한 시스템 간의 데이터 이질성을 해결하지 못한다. 따라서 이 논문에 서는 $\mathrm{MDR}$ 에 저장된 정보의 상호운용성을 위해 확장된 $\mathrm{MRA}$ 인터페이스를 제안한다. 이를 위해 확장된 $\mathrm{MRA}$ 의 구 현 시 적용되어야 하는 메타 모델들 간의 관계성들을 나열 하고 표준 질의 언어인 $\mathrm{SQL}$ 로 관계성을 표현하기 위한 방 법을 제안한다. 또한 구현 결과 및 평가 결과를 통해 제안 방법의 장점을 보인다.

\section{EMRA}

이 장에서는 $\mathrm{MRA}$ 의 문제점을 정의하고 이를 해결하기 위한 접근 방법을 기술한다. 또한 $\mathrm{MRA}$ 의 문제점을 개선한 $\mathrm{eMRA}$ 의 구현하기 위한 방법을 서술한다.

$\mathrm{MRA}$ 는 다양한 $\mathrm{MDR}$ 시스템에 등록되어 있는 데이터에 접근하기 위한 표준 인터페이스이다. 하지만 $\mathrm{MRA}$ 는 $\mathrm{MDR}$ 에 정의하고 있는 개념 즉, 클래스 간 관계성을 고려하지 않고, 각각의 클래스에 해당하는 사용자 정의 타입만을 제
공한다. 즉 $\mathrm{MDR}$ 에 정의된 클래스 간의 다양한 관계정보를 반영하지 못하므로 사용자들이 다양한 클래스로부터 데이터 를 접근하고자 할 경우 추가적인 비용이 요구된다.

Fig. 2는 $\mathrm{MDR}$ 에 정의된 클래스와 클래스들의 상속 관계 가 포함된 메타모델이다. Registered_Item은 Identified_Item 을 상속받으며 Administered_Item과 Attached_Item은 Registered_Item의 하위 클래스 관계다. 이처럼 $\mathrm{MDR}$ 에는 다양한 관계 정보가 정의되어 있다. 그러나 $\mathrm{MRA}$ 에서는 메 타 모델의 개념요소, 즉 클래스를 하나의 사용자 정의 타입 으로 사상하고 있을 뿐, 클래스들 간의 관계성에 대한 처리 방법이 없다. Table 1은 MRA에서 Fig. 2에 나타내고 있는 클래스들을 $\mathrm{MRA}$ 에서 정의한 것이다. Table 1에서 나타난 것처럼 Registered_Item 클래스와 Identified_Item 클래스 간 의 관계 정보가 정의 되어 있지 않기 때문에 상속관계 정보 가 누락되며, 사용자가 상위 클래스의 정보를 검색하기 위 해서는 추가적인 인터페이스의 구현이 요구된다.

따라서 제안하는 $\mathrm{eMRA}$ 는 이러한 추가적인 비용이 발생 하지 않도록 $\mathrm{MDR}$ 에 존재하는 관계정보를 반영해야한다. 먼 저, $\mathrm{MDR}$ 에 존재하는 관계정보를 나열하고 그것들을 구현하 는 방법을 상세히 서술한다.

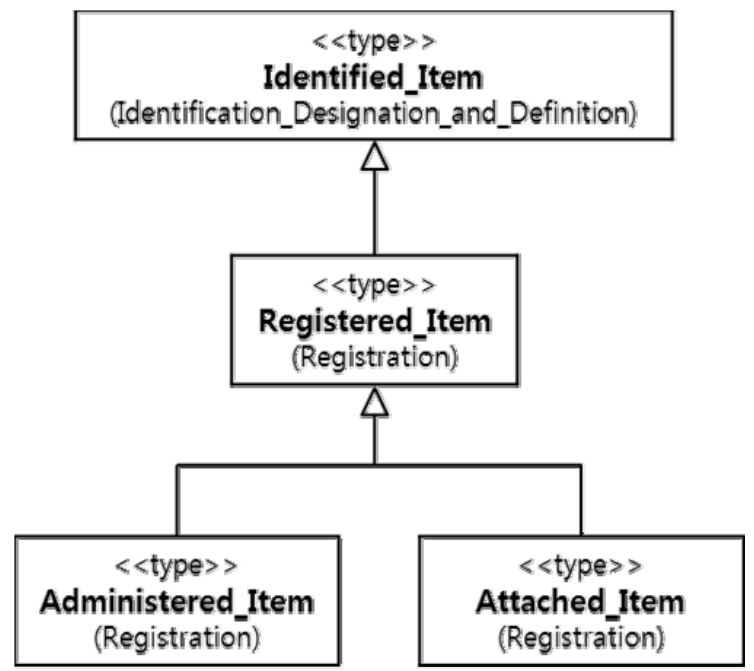

Fig. 2. Part of the MDR classes

Table 1. Specification of MDR concepts in the MRA

MRA_Identified_Item Type

CREATE TYPE MRA_Identified_Item AS(...)

MRA_Registered_Item Type

CREATE TYPE MRA_Registered_Item AS(...)

3.1 내포 구조 타입 (Nested structured type)

한 개의 타입에는 여러 개의 속성이 존재할 수 있으며, 각각의 속성은 자신의 데이터타입을 가진다. 데이터타입은 "Predefined type" 즉, 사전 정의된 타입과 사용자 정의 타 입으로 구분된다. 사전 정의된 타입이란 데이터베이스 시스 
템에 기본적으로 정의된 타입을 말하며 예로는 integer, char, date 등이 있다. 그러나 Fig. 3에 기술된 Computer 타 입은 사전 정의 타입이 아닌 사용자가 정의한 타입을 가지 는 속성들로 구성되어 있다. 다시 말해서, Input_Device, Output_Device가 내포 구조 타입이며, 내포 구조 타입은 다 른 타입의 속성 뿐 만 아니라 테이블의 속성으로 사용 가능 하며, 한 개의 사용자 타입 안에는 여러 개의 내포 타입이 정의될 수 있으며, 그 내포 타입 안에도 새로운 내포 타입 이 생성될 수 있다.

Table 2. Implementation example of nested structure type

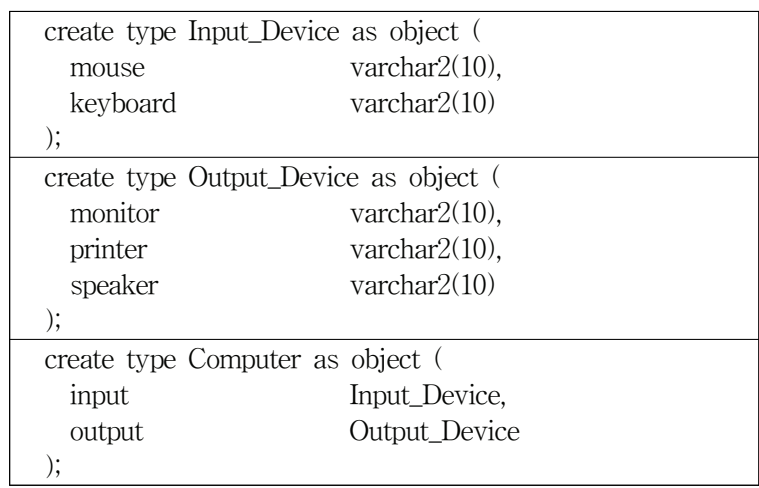

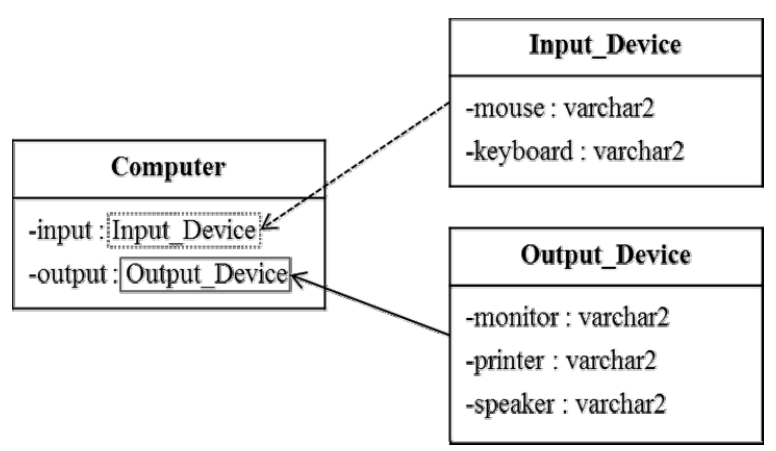

Fig. 3. Example of nested structure type relationship

Table 2는 내포 구조 타입을 생성하기 위한 문법이다. Computer 타입은 2개의 속성을 가지고 있는 것처럼 보이지 만 각 속성이 사용자 정의 타입으로 정의되어 있기 때문에, Input_Device와 Output_Device 타입이 가지고 있는 속성들 까지 모두 포함한다.

$\mathrm{MDR}$ 은 Fig. 4와 같이 한 개의 클래스 안에 다른 클래스 가 하나의 속성으로 정의되어 있는 관계들을 지닌다.

Fig. 4에서 Reference_Document는 MDR에서 정의한 하나 의 클래스로서, 사전 정의된 타입(Text, String)들과 사용자 정 의 타입(Organization, Language_Identification, Document_ Type)을 가진다. Table 3은 Fig. 4에서 보인 클래스들을 데이 터베이스에 구현한 것이다. Reference_Document 클래스를 사 용자 정의 타입으로 구현하기 위해 Organization, Language_ Identification, Document_Type, Notation 클래스들이 사전에 정의되어야 한다.

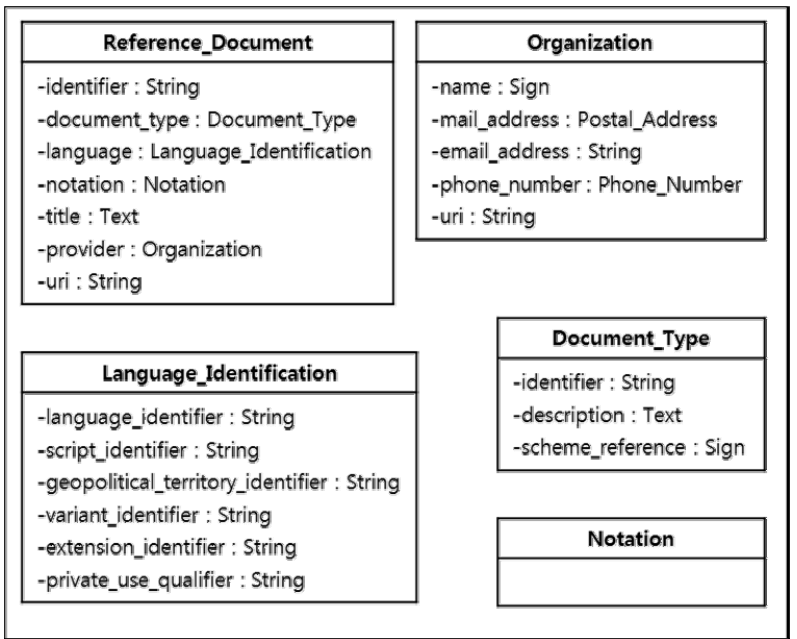

Fig. 4. Nested structure type relationships in the MDR

Table 3. Implementation of nested structure type within the MDR

\begin{tabular}{|ll|}
\hline $\begin{array}{l}\text { create type Notation as object ( } \\
\text { ); }\end{array}$ \\
\hline $\begin{array}{l}\text { create type Document_Type as object ( } \\
\text { identifier }\end{array}$ & string, \\
description & text, \\
scheme_reference & sign \\
); & \\
\hline create type Organization as object & sign, \\
name & Postal_Address, \\
mail_address & string, \\
email_address & Phone_Number, \\
phone_number & string \\
uri & \\
); & \\
\hline create type Language_Identification & as object ( \\
language_identifier & string, \\
script_identifier & string, \\
geopolitical_territory_identifier & string, \\
variant_identifier & string, \\
extension_identifier & string, \\
private_use_qualifier & string \\
); & \\
\hline create type Reference_Document & as object ( \\
identifier & string, \\
document_type & Document_Type, \\
language & Language_Identification, \\
notation & Notation, \\
title & text, \\
provider & Organization, \\
uri & string \\
); & \\
\hline & \\
\hline
\end{tabular}

\section{2 관계성 처리}

$\mathrm{MDR}$ 에는 연관관계(Association), 집합연관관계(Aggregation), 복합연관관계(Composition), 상속관계(Inheritance) 등을 통 해 클래스 간 관계성을 표현한다. 이 절에서는 $\mathrm{MDR}$ 에 표현 되어 있는 클래스 간의 관계성을 각각의 예제와 함께 MRA 인터페이스를 위한 해결방법에 대하여 서술한다. 


\begin{tabular}{|c|c|c|c|}
\hline Flight & \multirow{2}{*}{$0 .{ }^{*}$} & \multirow{2}{*}{ assignedPlane } & Plane \\
\hline -FlightNumber: int & & & - airPlaneTyne - string \\
\hline $\begin{array}{l}\text {-DepartureTime : date } \\
\text {-FlightDuration : time }\end{array}$ & assignedFlights & $0 . .1$ & $\begin{array}{l}\text {-airplanelype : string } \\
\text {-maximumSpeed : int }\end{array}$ \\
\hline
\end{tabular}

Fig. 5. Example of association relationship

\section{1) 연관관계 처리방법}

Fig. 5는 연관관계의 예를 보인다.

연관관계를 데이터베이스에 적용시키려면 기본 키 (Primary key), 외래 키(Foreign Key) 제약이 필요하다. 하 지만 기본 키, 외래 키 제약은 사용자 정의 타입을 생성할 때 지정할 수 없고, 사용자 정의 타입을 기반 한 테이블인 타입형 테이블(Typed table)을 선언 할 때만 키 제약조건을 지정할 수 있다. 타입형 테이블은 사용자 정의 타입을 기반 으로 실제 데이터를 물리적인 데이터베이스에 저장하기 위 한 것이다. Table 4 는 사용자 정의 타입과 그 사용자 정의 타입을 기반으로 한 타입형 테이블을 보인다.

Table 4. Creation example Test_table_PK

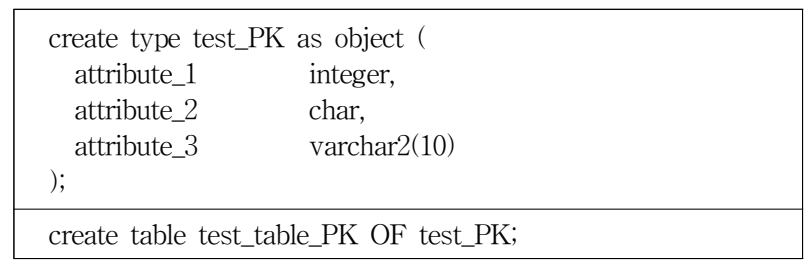

생성된 타입형 테이블은 test_PK 타입을 기반으로 한 테 이블이기 때문에 test_PK 타입의 속성을 모두 포함한다. 또 한 타입형 테이블인 test_table_PK를 생성할 때 기반이 되 는 타입인 test_PK 타입의 속성 외에 그 어떠한 다른 속성 도 추가할 수 없다. 선언된 타입형 테이블 table_PK 테이블 에 기본 키, 외래 키 제약 조건을 적용하는 예제는 Table 5 와 같으며, test_PK 타입에 명시되어 있는 attribute_1을 기 본 키로 지정한 예를 보인다.

Table 5. Example of Applying primary key

create table test_table_PK of test_PK (
primary key (attribute_1)
);

사용자 정의 타입 생성 시 기본 키를 지정할 수 없기 때 문에 타입형 테이블을 선언할 때 기본 키를 지정한다. 다음 은 Table 6에서 지정된 기본 키를 참조한 외래 키 정의 예 제다.

test_table_FK 테이블은 test_FK 타입을 기반으로 한 타 입형 테이블이고, 두 개의 속성attr_1, attr_2를 가진다. Table 6은 이 두 개의 속성 중, attr_2는 test_pk의 기본 키 를 참조한다. 그러므로 'foreign key(attr_2)' 구문을 이용하 여 attr_2를 외래 키로 지정하고 한다. 마지막으로, 'ON
Table 6. Foreign key definition example

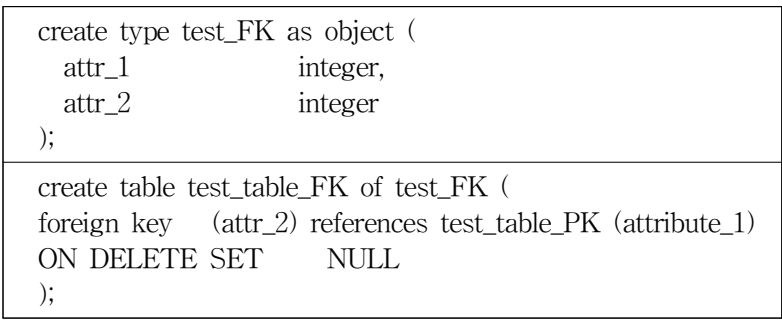

DELETE SET NULL', 'ON DELETE SET NULL' 제약을 추가함으로써 기본 키가 삭제되었을 때, 연관관계를 맺는 테이블의 외래 키 값들을 NULL 값으로 초기화 시키는 제 약사항이 추가된다. 이를 통해 두 테이블 간 관계를 삭제할 때 외래 키 값들은 NULL 값으로 변경시킨다.

Fig. 6은 앞에서 $\mathrm{MDR}$ 에 존재하는 연관관계 예를 보인다.

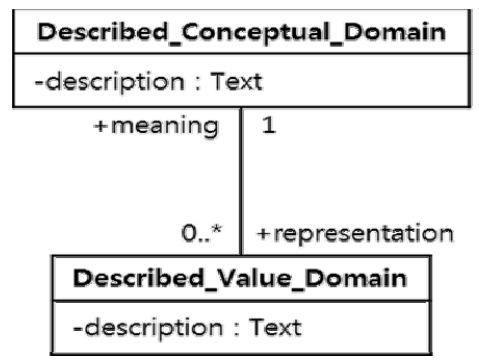

Fig. 6. Example of association relationship in the MDR

Table 7은 Fig. 6에서 보이는 연관관계를 구현을 위한 $\mathrm{SQL}$ 정의문을 보인다.

Fig. 6에서, Described_Conceptual_Domain 클래스는 Described _Conceptual_Domain_ID 속성을, Described_Value_Domain 클래스는 Described_Value_Domain_ID 속성을 각각 지닌다. 현재 $\mathrm{MDR}$ 표준에는 기본 키와 외래 키에 대한 명시가 없으 므로 이 논문에서는 각각의 클래스들을 식별할 수 있는 ID 값을 생성하여 기본 키로서 정의한다. 또한 기본 키를 참조 할 외래 키를 생성하여 기본 키와 외래 키 관계를 처리한다. Described_Value_Domain 클래스가 Described_Conceptual_ Domain 클래스를 참조하므로 Described_Conceptual_Domain 클래스를 기반으로 한 타입형 테이블인 TAB_Described Conceptual_Domain 테이블을 정의할 때, Described Conceptual_Domain_ID 속성을 기본 키로 정의하고, TAB Described_Value_Domain 테이블을 정의할 때, FK Described_Conceptual_Domain_ID속성을 외래 키로 지정한다. 
Table 7. Implementation of association relationship

\begin{tabular}{l}
\hline create type Described_Conceptual_Domain as object ( \\
Described_Conceptual_Domain_ID varchar2(20), \\
CD_description text \\
); \\
\hline create type Described_Value_Domain as object ( \\
Described_Value_Domain_ID varchar2(20), \\
FK_Described_Conceptual_Domain_ID varchar2(20), \\
VD_description text \\
); \\
create table TAB_Described_Conceptual_Domain of \\
Described_Conceptual_Domain( \\
primary key (Described_Conceptual_Domain_ID) \\
); \\
create table TAB_Described_Value_Domain of \\
Described_Value_Domain ( \\
foreign key (FK_Described_Conceptual_Domain_ID) \\
references TAB_Described_Conceptual_Domain \\
(Described_Conceptual_Domain_ID) ON DELETE SET \\
NULL \\
);
\end{tabular}

\section{2) 집합연관관계 및 복합연관관계 처리방법}

집합연관관계(Aggregation)와 복합연관관계(Composition) 는 연관관계의 특별한 형태로서, 먼저 집합연관관계를 데이 터베이스에 표현하기 위해서는 기본 키와 외래 키를 정의하 여 각 클래스의 생명주기의 독립성을 보장해야 한다. 복합 연관관계를 표현하기 위해서는 'ON DELETE CASCADE' 제약을 추가한다. 'ON DELETE CASCADE' 제약은 기본 키가 삭제되면 외래 키도 삭제시키는 제약으로서, 전체 클 래스와 부분 클래스의 생명주기가 같은 복합연관관계의 특 징을 반영한다. Fig. 7은 $\mathrm{MDR}$ 메타모델에 포함되어 있는 집합연관관계 및 복합연관관계의 예로서, Table 8은 이에 대한 처리를 위한 구현 방법을 보인다.

Table 9는 Fig. 7의 Dimensionality 클래스와 Unit_Of_ Measure 클래스의 집합연관관계를 구현한 것이다. 앞서 언

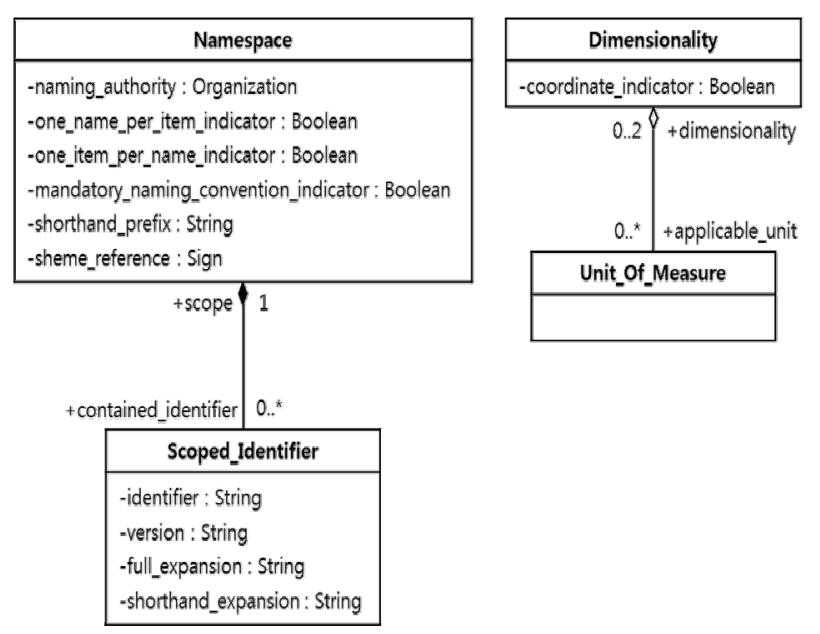

Fig. 7. Example of aggregation and composition relationship in the MDR
Table 8. Implementation of aggregation relationship

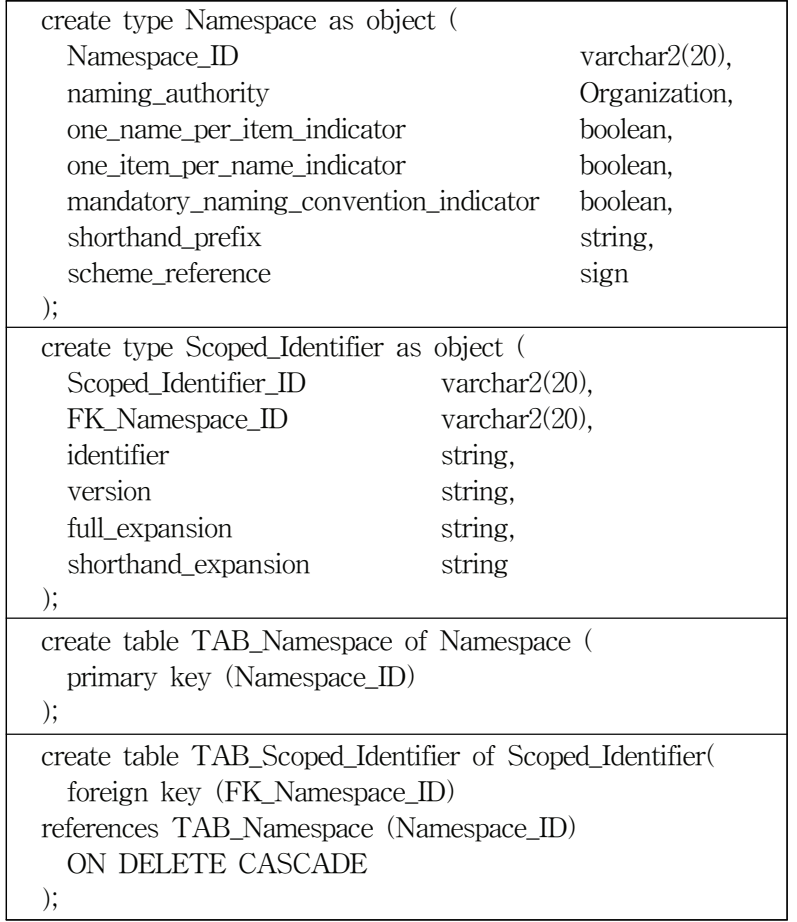

급하였듯이, 각각의 타입을 생성할 때 관계성을 반영할 수 없다. 그러므로 타입을 기반으로 한 타입형 테이블을 각각 생성함과 동시에 기본 키와 외래 키를 지정하고 제약을 추 가함으로써 관계성을 처리한다.

TAB_Unit_Of_Measure 테이블의 FK_Dimensionality_ID 속성을 외래 키로 지정한다. 이 속성은 $\mathrm{TAB}_{-}$ Dimensionality 테이블의 기본 키인 Dimensionality_ID 속성 에 사상한다. 오라클 $11 \mathrm{~g}$ 의 외래 키 제약은 기본적으로 ' $\mathrm{ON}$ DELETE NO ACTION'제약이 내포되어 있다. 이는 기본 키가 삭제되어도 외래 키는 아무 영향을 받지 않는 제약으 로서, $\mathrm{ISO} / \mathrm{IEC} 9075$ 제2부에 정의되어 있다. 그러므로 집합 연관관계는 기본 키와 외래 키 정의로써 데이터베이스에 표 현이 가능하다.

\section{3) 상속관계 처리방법}

객체 지향의 가장 중요한 개념 중 하나인 상속관계는 하 나의 클래스(자식 클래스)가 또 다른 클래스(슈퍼 클래스)를 상속 받았다면, 상속 받은 자식 클래스는 부모 클래스의 기 능을 그대로 이용할 수 있다는 것을 의미한다. 또한 자식클 래스는 부모 클래스에서 상속받은 기능 외에 자신만의 기능 을 정의하여 사용한다.

Fig. 8은 상속관계의 예다. Child 클래스는 Parent클래스 가 포함하는 속성 Parent_Attr1, Parent_Attr2, Parent_Attr3 을 모두 포함할 뿐 아니라 Child 클래스 고유의 속성인 Child_Attr1, Child_Attr2도 포함한다. 상속관계를 데이터베 이스에 표현할 때는 Table 10에서와 같이 'UNDER' 키워드 를 사용한다. 


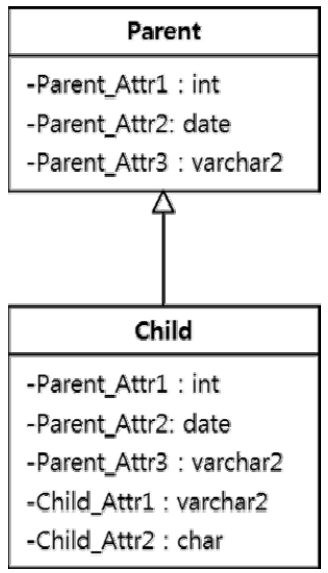

Fig. 8. Example of inheritance relationship

Table 9. Implementation of inheritance relationship

\begin{tabular}{|ll|}
\hline \multicolumn{2}{|c|}{ create type Parent as object ( } \\
Parent_Attr1 & int, \\
Parent_Attr2 & date, \\
Parent_Attr3 & varchar2 \\
); & \\
\hline create type Child as object UNDER Parent( \\
Child_Attr1 & varchar2, \\
Child_Attr2 & char \\
\hline
\end{tabular}

Table 10 과 같이 'UNDER' 키워드를 사용하여 상속관계 를 표현하였다. 그러므로 Child 타입은 Parent 타입의 속성 들을 모두 가지고 있기 때문에 Child 타입을 선언할 때 Parent 타입의 속성을 선언할 필요 없이 Child 고유의 속성 만 선언한다. Fig. 9는 MDR에 있는 상속관계다.

Organization 클래스를 상속받는 Registration_Authority 클래스는 Organization 클래스가 가진 속성을 가지고, 더불 어 자신만의 속성도 가진다. Table 11은 Fig. 9의 상속관계 예제에 대한 구현 결과를 보인다.

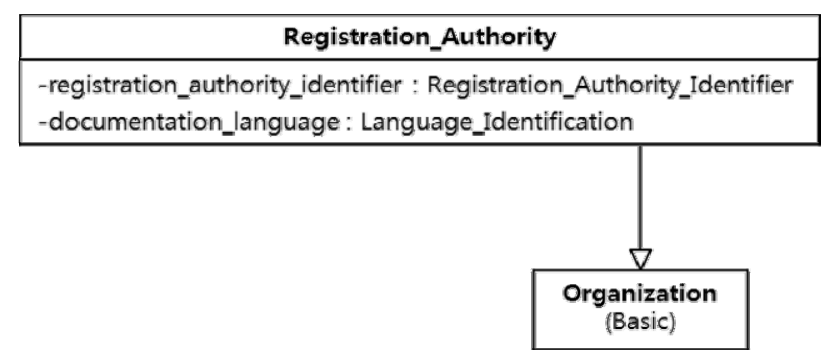

Fig. 9. Inheritance relationship in the MDR

앞서 언급한 'UNDER' 키워드로 Organization 타입을 상 속받은 Registration_Authority 타입을 생성한다. 생성된 Registration_Authority 타입은 자신이 포함하는 registration_authority_identifier, documentation_language 속 성 뿐 아니라 부모 타입인 Organization의 속성을 포함한다.
Table 10. Implementation of inheritance relationship

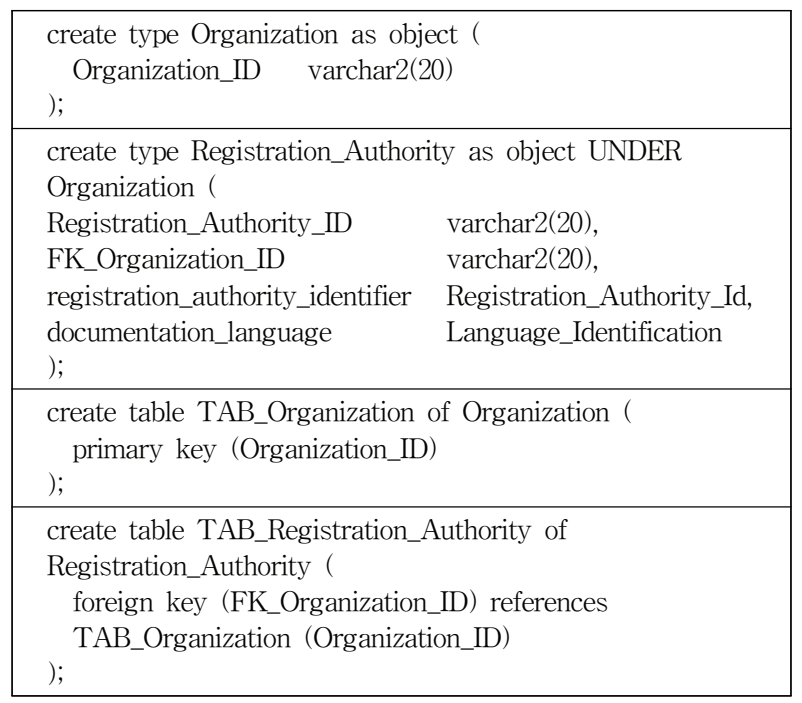

상속관계를 강건하게 하기 위해서 부모 클래스와 자식 클래 스에 각각 기본 키와 외래 키를 적용한다. 이를 통해 자식 클래스는 부모 클래스의 구조를 포함할 뿐 아니라 부모 클 래스와의 연관성도 도출할 수 있다.

\section{4. 실험 및 비교평가}

\section{1 스키마 구조}

실험 평가를 위해서는 $\mathrm{MDR}$ 시스템을 구축해야 한다. 이 논문에서는 $\mathrm{MDR}$ 시스템의 프로토타입을 구현하며, 구현을 위한 DBMS로는 Oracle $11 \mathrm{~g}$ 를 이용한다. Fig. 10은 구축된 시스템의 스키마 구조를 보여 주며, 스키마는 앞서 기술한 $\mathrm{MDR}$ 에 존재하는 관계정보(연관관계, 집합연관관계, 복합연 관관계, 상속관계)를 명확하게 반영한다.

\section{2 실험 및 평가 결과}

이 절에서는 $\mathrm{MRA}$ 와 $\mathrm{eMRA}$ 의 질의처리 효율성을 비교하 기 위한 실험을 수행하여 평가한다. 비교 평가 항목은 질의 모델링 시간과 질의문 필터링 개수로 구분한다.

질의 모델링 시간은 시스템에 질의하는 전체 과정을 의미 한다. MRA와 $\mathrm{eMRA}$ 시스템에 질의를 수행할 때 관계정보 의 반영이 어떤 영향을 미치는지를 비교한다. 이 논문에서 는 MRA에 관계정보를 포함한 질의를 수행할 때 추가적인 연산이 요구되기 때문에 eMRA에서 질의를 수행하는 시간 보다 많은 시간이 소요될 것이라고 가정한다.

질의문 필터링 개수는 시스템의 신뢰성을 측정하는 평가 요소이다. 관계정보를 반영함으로 인해 MRA와 $\mathrm{eMRA}$ 에 질 의를 수행했을 때 보이는 결과의 차이를 비교한다. $\mathrm{eMRA}$ 는 $\mathrm{MDR}$ 의 관계정보를 반영하므로 관계성을 고려한 질의를 수 행할 때 누락되어야 하는 결과를 올바르게 누락시킨다고 가 정한다. 그러나 $\mathrm{MRA}$ 는 관계정보를 반영하지 않는다. 따라 서 결과에서 제거되어야 하는 정보를 누락시키지 않고 도출 


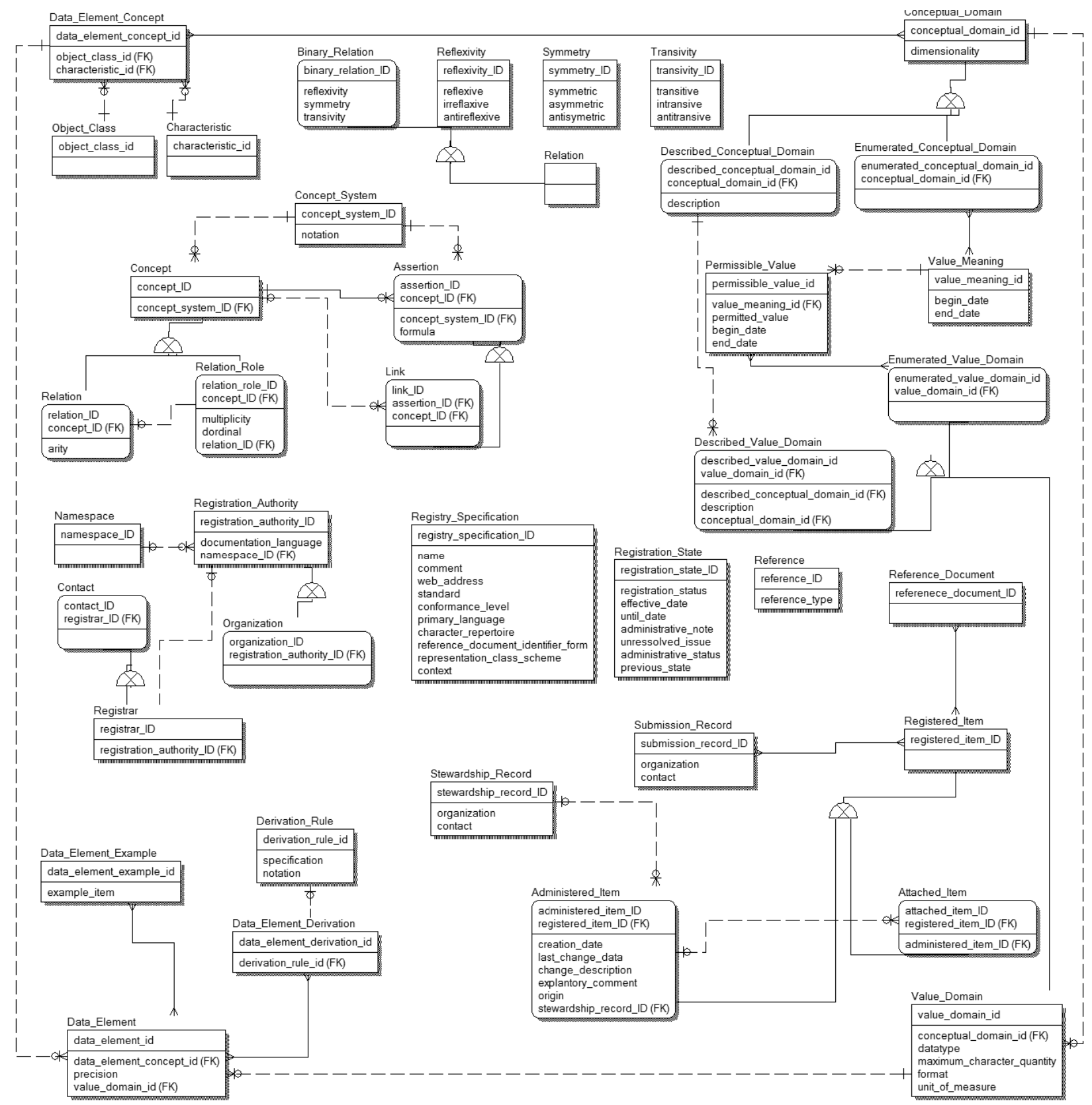

Fig. 10. The schema structure of proposed interface

한다고 가정한다. 실험을 위해 다음과 같은 전제조건을 정 의한다. 먼저, $\mathrm{MRA}$ 와 $\mathrm{eMRA}$ 는 관계정보의 유무를 제외한 나머지 조건은 동일하다. 나머지 조건은 테이블의 이름, 수, 테이블 내 존재하는 속성의 이름과 수 그리고 저장된 데이 터를 모두 포함한다. 또한 $\mathrm{MDR}$ 표준에 정의된 클래스는 하 나의 테이블로 구축한다.

시스템에 수행하는 질의는 단순 검색질의와 복합 검색질 의로 구분하여 정의한다. 복합 검색질의는 연관관계, 집합연 관관계, 복합연관관계, 상속관계를 포함한다. 단순 검색질의 는 단일 테이블에서 데이터를 검색하는 질의다. 반면 복합 검색질의는 두 개 이상의 테이블에서 관계성을 고려하여 데 이터를 검색하는 질의다. 따라서 MRA 시스템에서 복합검색
질의를 수행시켜 정확한 결과를 얻으려 한다면 결과데이터 를 정제하는 추가적인 연산이 요구된다.

\section{1) 질의 모델링 시간}

이 절에서는 3.2 절에서 정의한 질의 유형을 바탕으로 실 제 시스템에 질의하는 과정을 정의한다. 또한 정의한 과정 을 수식화하여 $\mathrm{MRA}$ 와 $\mathrm{eMRA}$ 시스템의 질의처리 효율성을 비교한다. 실험은 수식화한 질의 모델링 과정을 시뮬레이션 을 통해 시간을 측정한다.

사용자는 시스템에 질의하기 위해 크게 다음 4단계의 과 정을 거친다.

1. 메타데이터추출: 메타모델 정보를 분석하는 과정 
2. 관계정보확인: 실제 데이터베이스시스템에 접근하여 릴레 이션과 속성을 검색하고 관계정보가 정의되어있는지 확인 하는 과정

3. 관계정보생성: 관계정보가 정의되어 있지 않은 경우 시스 템에 관계정보를 정의하는 과정

4. 질의생성: 질의를 수행하는 과정

메타데이터추출 과정에서는 논리적인 메타모델의 정보를 분석하고 클래스의 상세한 정보도 분석 가능하다. 상세한 정보란 속성의 개수, 속성의 데이터타입, 관계정보를 포함한 다. 사용자는 첫 번째 과정을 거친 후에 어떤 클래스의 어 떤 속성을 검색할 것인지 결정할 수 있다. 또한 복합 검색 질의를 할 경우, 질의에 포함시킬 관계정보 개수도 결정 가 능하다. 그 후 사용자는 실제 데이터베이스 시스템에 접근 하여 일치하는 릴레이션과 속성을 검색해야한다.

관계정보확인 과정에서는 데이터베이스에 접근하여 릴레 이션과 속성을 검색하고 메타모델에서 분석한 클래스와 속 성이 일치하는지 확인한다. 또한 관계정보가 데이터베이스 에 정의되어 있는지 확인한다. 만약 관계정보가 정의되어 있지 않으면 복합 검색질의를 할 수 없다. 따라서 관계정보 가 정의되어 있지 않은 시스템에서 복합검색 질의를 수행하 려면 추가적인 연산이 필요하다. 관계정보생성 과정에서는 앞서 수행한 관계정보가 정의되어 있지 않을 경우 수행하는 과정이다. $\mathrm{MRA}$ 시스템은 $\mathrm{MDR}$ 에 명시된 관계정보를 정의 하고 있지 않으므로 복합 검색질의를 수행할 수 없다. 따라 서 복합 검색질의를 수행할 수 있도록 관계정보를 생성해야 한다. 그러나 제안한 $\mathrm{eMRA}$ 시스템은 $\mathrm{MDR}$ 에 명시된 관계 정보를 명확하게 정의했기 때문에 관계정보를 확인하는 단 계부터 생성하는 단계까지의 과정을 수행할 필요가 없다. 질의생성 과정에서는 실제 데이터베이스 시스템에 질의를 입력하여 결과 값을 도출하기까지의 모든 과정이다. 이 과 정을 수식으로 나타내기 위해 Table 11에서는 MRA 시스템 과 $\mathrm{eMRA}$ 시스템에 질의하는 과정을 비교하기 위한 변수 정의를 보인다.

Table 11. Variables that are used in query modeling and description

\begin{tabular}{|c|c|}
\hline Variable & Description \\
\hline tQD & Query modeling time \\
\hline tMA & $\begin{array}{c}\text { Required time that analyze metamodel } \\
\text { that included in the query }\end{array}$ \\
\hline tRS & $\begin{array}{c}\text { The number of relationship between relations } \\
\text { the relation of database. }\end{array}$ \\
\hline tAS & $\begin{array}{c}\text { Time comparison of the class attribute of } \\
\text { metamodel and the relation attribute of database. }\end{array}$ \\
\hline tCR & $\begin{array}{c}\text { The required time to confirm whether the } \\
\text { relationship is participate in relations is defined } \\
\text { in database }\end{array}$ \\
\hline tGR & Relationship generated time \\
\hline tQC & Query execution time \\
\hline
\end{tabular}

Table 11에서 정의한 변수들을 이용하여 MRA 시스템에 질의하기 위한 과정을 나타내면 수식 1 과 같다. 앞서 언급 하였듯이 질의모델링은 메타모델 분석 과정, 실제 데이터베 이스 시스템에 접근하여 릴레이션과 속성을 확인하는 과정 및 질의 수행 과정을 포한한다. $\mathrm{MRA}$ 시스템은 $\mathrm{MDR}$ 의 관 계정보가 반영되어있지 않기 때문에 관계정보가 정의되어있 는지 확인하는 시간이 요구된다. 또한 관계정보가 정의되어 있지 않을 경우 필요한 수만큼 관계를 정의하는 시간이 추 가로 요구된다. 이 시간은 질의에 포함되는 관계정보 개수 가 많아질수록 증가한다.

$$
t Q D=t M A+t R S+t A S+\sum_{i=1}^{n R} t C R_{i}+\sum_{j=1}^{n R} t G R_{j}+t Q C
$$

이 논문에서 제안한 $\mathrm{eMRA}$ 는 $\mathrm{MDR}$ 의 관계정보를 이미 반영했기 때문에 질의 모델링 시간을 단축시킨다. 수식 2 는 $\mathrm{eMRA}$ 시스템에 질의 시간을 계산하는 수식이다. eMRA는 관계정보를 반영했기 때문에 관계정보가 정의되어있는지 확 인하고 생성하는 절차를 생략할 수 있다. 따라서 메타모델 을 분석한 후, 데이터베이스 시스템에 접근하여 릴레이션과 속성을 확인하는 과정이 완료되면 바로 질의를 수행할 수 있다. eMRA 시스템의 질의 모델링에서는 관계정보 개수가 전체 모델링 시간에 영향을 주지 않는다. 따라서 전체 질의 모델링 시간이 단축된다.

$$
t Q D=t M A+t R S+t A S+t Q C
$$

Fig. 11은 관계정보 개수에 따른 질의 모델링 시간을 비 교한 그래프이다. 질의모델링 시간은 과정에 개입하는 사람 의 개인차에 의존적이기 때문에 수식에 사용되는 변수는 0 부터 1 사이의 랜덤 값으로 실험한다. 또한 충분한 시뮬레이 션을 통해 보다 신뢰성 있는 결과를 내기 위해 총 100번의 실험을 거쳐 평균값을 계산한다.

$\mathrm{eMRA}$ 는 $\mathrm{MDR}$ 의 관계정보를 반영했기 때문에 관계정보 가 정의되어있는지 확인하고 생성하는 시간 $\left(\sum_{j=1}^{n R} t G R_{j}\right.$, $\left.\sum_{i=1}^{n R} t C R_{i}\right)$ 이 생략된다. 따라서 질의에 포함된 관계정보의 개 수 $n R$ 의 개수가 증가해도 전체 질의 모델링 시간은 증가 하지 않는다. 반면 $\mathrm{MRA}$ 는 $n R$ 의 개수가 증가할수록 $\sum_{j=1}^{n R} t G R_{j}$ 과 $\sum_{i=1}^{n R} t C R_{i}$ 이 증가하게 되므로 질의 모델링 시간이 증가한다. 실험 결과, 관계정보의 개수가 많아질수록 큰 차 이가 나는 것을 확인하였고 $\mathrm{eMRA}$ 는 관계정보개수에 영향 받지 않는 것을 확인하였다.

\section{2) 질의문 필터링 개수}

이 절에서는 삽입, 삭제, 갱신에 관한 질의를 통해 $\mathrm{eMRA}$ 의 질의 처리 결과에 대한 정확성을 평가한다. eMRA의 참 조무결성 여부를 판단하기 위해 삽입, 삭제, 갱신 질의를 수 행한 결과를 평가요소로 정의하였다. $\mathrm{MRA}$ 시스템은 $\mathrm{MDR}$ 


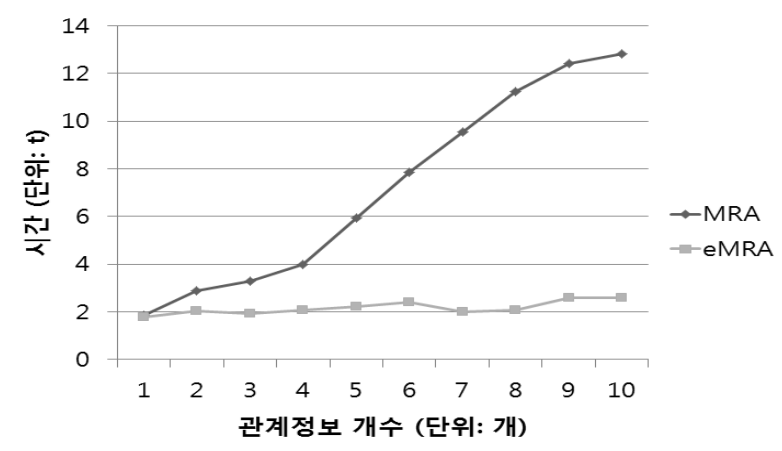

Fig. 11. Time comparison of query modeling in MRA and eMRA

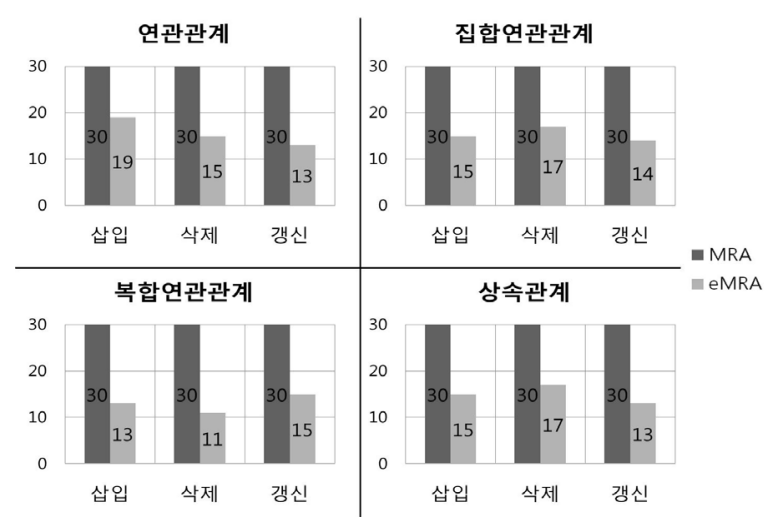

Fig. 12. Query results of each relationship

의 관계정보를 반영하지 않으므로 질의 결과에서 누락되어 야 하는 정보들이 누락되지 않는다. 이는 시스템의 신뢰도 를 하락시키는 요인이 된다.

Fig. 12 는 MRA와 $\mathrm{eMRA}$ 를 기반으로 한 시스템에 삽입, 삭제, 갱신에 관한 질의를 각각 30 개씩 샘플링하여 시스템 에 질의한 후, 질의가 실제 수행된 횟수를 비교하였다. 각 질의는 관계성을 반영한 단일 테이블에 실행하는 질의다. Table 12은 각 질의에 대한 상세설명이다.

Table 12. Insert, delete, update query

\begin{tabular}{|c|c|c|}
\hline Query & \multicolumn{2}{|c|}{ Description } \\
\cline { 2 - 4 } insert & type & Query that add a new tuple in table \\
\hline delete & query & $\begin{array}{c}\text { Primary key must be unique in table, so if } \\
\text { added tuple has a duplicate primary key, } \\
\text { system should stop the execution }\end{array}$ \\
\cline { 2 - 4 } & type & $\begin{array}{c}\text { Query to remove the existing tuple in the } \\
\text { table }\end{array}$ \\
\hline update & type & $\begin{array}{r}\text { If there is a foreign key that references the } \\
\text { primary key in another table, system } \\
\text { should stop the execution }\end{array}$ \\
\cline { 2 - 4 } & query & $\begin{array}{c}\text { The system should stop the execution if } \\
\text { changed primary key is duplicated, or if } \\
\text { there is a foreign key that reference the } \\
\text { primary key in another table }\end{array}$ \\
\hline
\end{tabular}

$\mathrm{eMRA}$ 를 적용한 시스템은 참조 무결성 제약조건과 관계 정보를 반영하였기 때문에, 제약 조건을 위배하는 질의가 수행될 수 없다. 이 논문에서는 이러한 특성을 질의 필터율 이라 정의한다. 즉, 질의 필터율이란 관계성에 어긋나는 질 의가 수행되었을 때 시스템에서 얼마나 질의를 걸러낼 수 있는지에 대한 특성을 의미한다. Fig. 13에서 MRA의 질의 필터율은 $0 \%$ 인 것에 반해, $\mathrm{eMRA}$ 에서는 평균 $33.75 \%$ 의 필 터율을 보였다. eMRA에서는 참조 무결성 제약 조건이 반영 되었기 때문에 데이터의 삽입 삭제 갱신의 질의들이 필터링 됨을 알 수 있다. 기본적으로 클래스들 간의 상속관계는 다 른 관계와는 달리 기본 키 제약을 적용하지 않아도 관계를 정의할 수 있기 때문에 삭제, 갱신 질의에 문제가 없다. 그 러나 상속받는 자식 테이블은 부모 테이블의 속성도 포함하 고 있다. 따라서 데이터를 삽입하는 경우, 자식 테이블의 속 성과 부모 테이블의 속성 모두를 반영하여 데이터를 삽입하 지 않으면 에러가 발생한다. eMRA는 이렇게 에러가 발생되 는 질의를 필터링함으로써, 시스템 전체의 참조무결성을 보 장하고 표준 인터페이스의 역할을 완전하게 수행한다.

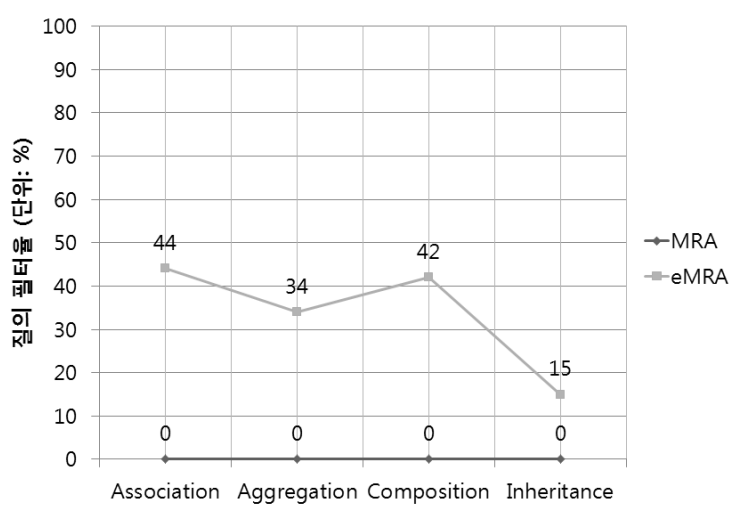

Fig. 13. Query filter rate

\section{5. 결론 및 향후 연구}

ISO/IEC $11179 \mathrm{MDR}$ 표준은 메타데이터를 등록하고 인 증하여 표준화된 데이터를 유지 및 관리하기 위해 제정되었 다. 또한 표준화된 데이터의 관리를 통해 상호운용성을 향 상시킬 수 있다. 이러한 장점을 통해 의료, 서지, 환경, 국방 등 다양한 분야에서 $\mathrm{MDR}$ 을 기반으로 한 시스템을 개발하 고 운영하고 있다. 그러나 $\mathrm{MDR}$ 표준은 논리적인 모델만 명 시할 뿐 구체적인 물리적 구현모델을 제공하고 있지 않다. 따라서 개발된 시스템들이 $\mathrm{MDR}$ 표준을 기반으로 하고 있 음에도 불구하고 서로 다른 구조와 접근방법을 가진다. 그 결과 다양한 $\mathrm{MDR}$ 에 대한 일관된 접근을 어렵게 하고 재사 용성 및 활용성 저하를 야기한다. 이러한 문제점을 해결하 기 위해 ISO/IEC 13249-8 MRA가 제안되었다.

$\mathrm{MRA}$ 는 $\mathrm{MDR}$ 을 기반으로 한 시스템에 접근할 수 있는 표준 인터페이스를 제안한다. 그러나 $\mathrm{MRA}$ 는 $\mathrm{MDR}$ 에 접근 하기 위한 기본적인 데이터타입만을 제공한다. $\mathrm{MDR}$ 표준에 
는 클래스와 클래스 사이에 존재하는 관계정보가 존재한다. 이러한 관계정보를 시스템이 반영하지 않는다면 질의처리 효율성이 저하된다. 따라서 질의처리의 효율성을 높이기 위 해 추가적인 연산이 요구된다.

따라서 이 논문에서는 기존 연구의 문제점을 극복할 수 있는 확장된 인터페이스 $\mathrm{eMRA}$ 를 제안하였다. $\mathrm{MDR}$ 표준에 존재하는 4 가지 관계정보(연관관계, 집합연관관계, 복합연관 관계, 상속관계)를 시스템에 적용할 수 있도록 구현하였다. 제안한 $\mathrm{eMRA}$ 의 질의처리 효율성을 평가하기 위해 관계정 보를 반영하지 않은 $\mathrm{MRA}$ 와 비교하였다. 평가항목으로서 질 의 모델링 시간과 질의문 필터링 개수를 정의하였다. $\mathrm{eMRA}$ 는 $\mathrm{MDR}$ 의 관계정보를 반영함으로써 관계정보 확인 단계와 관계정보 생성 시간을 생략함으로써 질의 모델링의 효율성 을 보였다. 또한 관계정보 반영으로 인해 시스템의 참조무 결성이 보장되었고, 이를 통해 복합 검색질의를 수행하였을 때 MRA에 비해 높은 정확성을 보였다.

이 논문은 기존 $\mathrm{MRA}$ 가 가지고 있던 문제점인 관계정보 를 적용하지 않았다는 점을 개선하여 표준 인터페이스로서 의 가치를 높였다. 이를 통해 서론 부분에서 소개한 다양한 방면에서 사용되고 연구되고 있는 $\mathrm{MDR}$ 시스템에 적용 가 능하다. 각 시스템은 $\mathrm{MDR}$ 을 기반으로 구축되었기 때문에 제안한 $\mathrm{eMRA}$ 를 적용할 수 있다.

이 논문에서는 오라클을 이용한 구현 모델을 보였다. 향 후에는 보다 다양한 데이터베이스 모델 및 데이터베이스 관 리시스템을 이용한 구현 모델을 개발하고 각각의 특징에 대 한 연구가 요구된다.

\section{참 고 문 헌}

[1] R. K. Pon, D. J. Buttler, "Metadata Registry, ISO/IEC 11179," Encyclopedia of Database Systems, pp.1724-1727, 2009.

[2] Y. Park, J. Kim, "Metadata registry and management system based on ISO 11179 for cancer clinical trials information system," Proc. of the AMIA Annual Symposium Proceedings, Vol.2006, pp.1056, 2006.

[3] J. Davies, S. Harris, Ch. Crichton, A. Shukla, J. Gibbons, "Metadata standards for semantic interoperability in e-government," Proc. of the 2nd International Conference on Theory and Practice of Electronic Governance, pp.67-75, 2008.

[4] J. Ostausberg, M. Löbe, P. Verplancke, J. Drepper, H. Herre, M.Löffler, "Foundations of a Metadata Repository for Databases of Registers and Trials," Proc. of European Federation for Medical Informatics, pp.409-413, 2009.

[5] L. Bountouri, C. Papatheodorou, V. Soulikias, M. Stratis, "Metadata interoperability in public sector information," Journal of Information Science, Vol.35, No.2, pp.204-231, 2008.

[6] D. Shin, E. Jeong, D. Jeong, S. Park, D. Baik, "A Model for Metadata Registry Management Systems," Proc. of Korea Society for Simulation Fall Conference, pp.173-177, 2003.

[7] D. Shin, D. Jeong, Y. Kim, S. Park, D. Baik, "A Query
Language for Consistent Access of Metadata Registries," Journal of Korea Information Science Society: Databases, Vol.2, No.1, pp.609-623, Dec., 2004.

[8] Australian Institute of Health and Welfare, Metadata Online Registry (METeOR), http://meteor.aihw.gov.au/ (accessed September 2012).

[9] US Health organizations (multiple), US Health Information Knowledgebase (USHIK), http://ushik.ahrq.gov (accessed September 2012).

[10] US Environmental Protection Agency, Environmental Data Registry, http://www.epa.gov/edr/ (accessed September 2012).

[11] US National Cancer Institute, Cancer Data Standards Repository (caDSR), http://ncicb.nci.nih.gov/NCICB/ (accessed September 2012).

[12] U.S. Department of Homeland Security (DHS) and U.S. Department of Justice (DOJ), US National Information Exchange Model (NIEM), http://www.niem.gov/ (accessed September 2012).

[13] US Department of Justice, Global Justice XML Data Model (GJXDM), http://www.it.ojp.gov/ (accessed September 2012).

[14] The Library of Congress(LC), http://www.loc.gov/ (accessed September 2012).

[15] Canadian Institute for Health Information, CIHI Data Dictionary, $\quad$ http://secure.cihi.ca/cihiweb/splash.html (accessed September 2012).

[16] UK Cancer Grid, Cancer Grid Metadata Registry, http://www.cancergrid.org/ (accessed September 2012).

[17] UK Office for Library Networking(UKOLN), http:// www.ukoln.ac.uk/ (accessed September 2012).

[18] D. Baik, Y. Choi, S. Park, J. Lee and D. Jeong, "A 3-Layered Information Integration System based on MDRs End Ontology," The KIPS transactions: Part D, Vol.10, No.2, pp.247-260, 2003.

[19] J. Kim, H, Park, C. Moon and D. Baik, "Design and Implementation of A Distributed Information Integration System based on Metadata Registry," The KIPS transactions: Part D, Vol.10, No.2, pp.233-246, 2003.

[20] J. Kim, D. Jeong, J. Kim and D. Baik, "Implementation of the Metadata Registry-based Framework for Semantic Interoperability of Application in Ubiquitous Environment," Journal of Korea Society for Simulation, Vol.16, No.1, pp.11-19, 2007.

[21] D. Jeong, H. Jeong, J. Kim, "A Study on Standardization of Query Processing of Metadata Registries," Proc. of the 2010 The Korea Society of Computer and Information Winter Conference, Vol.18, No.2, pp.65-68, 2010.

[22] J. Melton, A. Eisenberg, "SQL Multimedia and Application Packages (SQL/MM)," Proc. of Association of Computing Machinery SIGMOD Record, Vol.20, No.4, pp.97-102, 2001. 
[23] ISO/IEC 20944 Information technology - Metadata Registries Interoperability and Bindings (MDRIB), http://jtc1s32.org (accessed September 2012).

[24] P. Jyotichman, P. Lee, G.C. Christopher, B. Olivier, "Comparing and evaluating terminology services application programming interfaces: RxNav, UMLSKS and LexBIG," Journal of the American Medical Infor-matics Association (JAMIA), Vol.17, No.6, pp.714-719, 2010.

[25] ISO/IEC 9075 Information technology - Database languages - SQL - Part 2: Foundation (SQL/Foundation), http:// jtc1s32.org (accessed September 2012).

[26] ISO/IEC 13249 Information technology - Database languages - SQL Multimedia and Application Packages - Part 8: Metadata Registry Access, http://jtc1s32.org (accessed September 2012).

[27] D. Jeong, H. Jeong, J. Kim, K. Jeon, S. Shin, "Development of the SQL/MM Standard for Metadata Registries," Journal of the Korea Society of Computer and Information, Vol.15, No.9, pp.9-18, Sep., 2010.

[28] Y. Joo, S. Lee, J. Kim, D. Jeong, D. Baik, "An Implementation of ISO/IEC 13249-8 with Oracle," Proc. of the Korea Computer Congress 2011, Vol.38, No.1(A), pp.120-123, 2011.

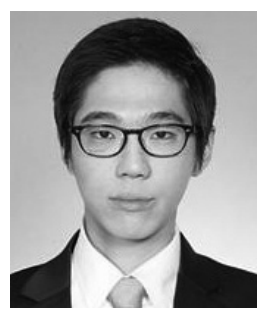

\section{주 영 민}

e-mail :wndudals77@korea.ac.kr 2011년 고려대학교 컴퓨터정보학과(학사) 2010년 현 재 고려대학교 컴퓨터 - 전파 통신공학과 석사과정

관심분야: 데이터베이스, 메타데이터 레지 스트리, 표준 인터페이스

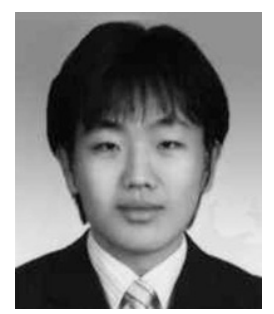

\section{김 장 원}

e-mail : ikaros1223@korea.ac.kr 2005년 상명대학교 소프트웨어공학과(학사) 2005년 한국과학기술연구원(KIST) 위촉연구원

2008년 고려대학교 컴퓨터학과(석사) 2012년 고려대학교 컴퓨터학과(박사) 관심분야: 온톨로지, 시맨틱 웹, GIS, 데이터베이스, 메타데이터 등

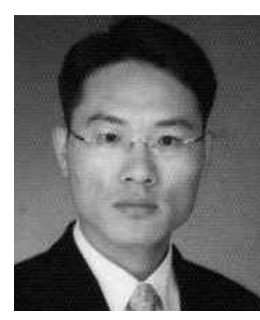

\section{정 동 원}

e-mail : djeong@korea.ac.kr 1997년 군산대학교 컴퓨터과학과(이학사) 1999년 충북대학교 전산학과(이학석사) 2004년 고려대학교 컴퓨터학과(이학박사) 1998년 전자통신연구원 위촉연구원 1999년 2000년 ICU부설 한국정보통신 교육원 GIS 분원 전임강사
2000년 2001년 (주)지구넷 부설 연구소 선임연구원 2002년 2005년 라임디미디어 테크놀로지 부설 연구소 연구원 2004년 2005년 고려대학교 정보통신기술연구소 연구조교수

2005년 Pennsylvania State University PostDoc

2002년 2004년 TTA 표준화위원회-데이터연구회(SG08.02) 특별위원

2004년 현 재 TTA 표준화위원회-메타데이타 표준화 프로 젝트 그룹(PG406) 위원

2005년 현 재 군산대학교 정보통계학과 교수

2006년 현 재 데이터관리서비스 전문위원회(ISO/IEC JTC 1/SC 32 Mirror Committee) 위원

2008년 현 재 지리정보 전문위원회(ISO/TC 211 Mirror Committee) 위원

2009년 현 재 TTA 표준화위원회-NGIS 프로젝트그룹 (PG409) 위원

2010년 현 재 인터넷윤리실천협회 이사

2010년 현 재 ICDL Korea 교수위원

2010년 현 재 전북지역 과학기술정보협의회 위원

2010년 현 재 한국과학기술정보연구원 자문위원

2010년 현 재 한국컴퓨터교육학회 이사

관심분야: 데이터베이스, 시맨틱 웹, 시맨틱 GIS, 유비쿼터스 컴퓨팅, 시맨틱 모바일 서비스, 클라우드 컴퓨팅

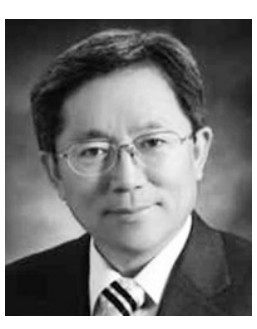

\section{백 두 권}

e-mail : baikdk@korea.ac.kr 1974년 고려대학교 수학과(학사) 1977년 고려대학교 산업공학과(석사) 1983년 Wayne State Univ. 전산학과 (석사)

1985년 Wayne State Univ. 전산학과 (박사)

1986년 현 재 고려대학교 컴퓨터·전파통신공학과 교수 1991년 현 재 (사)한국시뮬레이션학회 (이사/부회장/감사/회장 /고문)

1991년 현 재 ISO/IEC JTC1/SC32 전문위원회(위원장)

1999년 2000년 고려대학교 컴퓨터과학기술연구소(소장)

1999년 1999년 한국 DB 진흥센터 (표준연구위원)

2000년 2003년 소프트웨어 컴포넌트 표준화 포럼(부의장)

2001년 현 재 (사)도산아카데미(원장)

2002년 2004년 고려대학교 정보통신대학(초대학장)

2004년 2005년 (사)정보처리학회(부회장)

2004년 현 재 한국 프로젝트 관리 연구회(회장)

2009년 2010년 고려대학교 정보통신대학 학장

관심분야: 메타데이터, 소프트웨어공학, 데이터공학, 컴포넌트 기반 시스템, 메타데이터 레지스트리, 프로젝트 매니 지먼트 등 